\title{
Design and validation with finite element analysis of a veterinary application prosthesis for Cervus Nippon
}

\section{Diseño y validación con análisis de elementos finitos de una prótesis de aplicación veterinaria para Cervus nippon}

\author{
MONTIJO-VALENZUELA, Eliel Eduardo ${ }^{1,}$ RUIZ-NAVARRO, Alan Gustavo², \\ SILVA- CONTRERAS, Abraham ${ }^{3}$, RUBALCAVA-ARANDA, Javier Alejandro ${ }^{4}$ \\ SAMANO-HERMOSILLO, Efren ${ }^{5}$
}

\begin{abstract}
${ }^{1}$ Universidad Estatal de Sonora - Jefatura de Ingeniería en Mecatrónica.*Autor corresponsal. eliel.montijo@ues.mx / https://orcid.org/0000-0001-8538-0767

${ }^{2}$ Universidad de Sonora. Estudiantes de la Maestría en Nanotecnología, Departamento de Física. a221230219@unison.mx
\end{abstract}

${ }^{3}$ Centro de Investigación Científica y de Educación Superior de Ensenada, Baja California. Estudiantes de la Maestría en Ciencias en Nanociencias. abrahamsc@ cicese.edu.mx

${ }^{4}$ Tecnológico Nacional de México/Instituto Tecnológico de Hermosillo. Departamento de Ingeniería Biomédica. javier.aranda43@gmail.com

${ }^{5}$ Universidad Estatal de Sonora - Ingeniería en Software. efren.samano@ues.mx

\section{DOI: https://doi.org/10.46589/rdiasf.vi36.419}

Recibido 29 de agosto 2021.

Aceptado 29 de octubre 2021

Publicado 31 de octubre 2021

\begin{abstract}
This article presents results of static, thermal and stress analysis for a prosthesis design with veterinary applications based on a female Cervus nippon as a subject of study, in order to return the quality of life to those animals that have suffered an amputation and also recover the
\end{abstract}


capability to perform their activities throughout their lives. The model developed for this article is about giving an alternative to the rigid prostheses that are currently handled.

Keywords: Prosthesis, design, finite element analysis.

\section{Resumen}

Este artículo presenta los resultados del análisis estático, térmico y de estrés para un diseño de prótesis con aplicaciones veterinarias basadas en un Cervus nippon femenino como tema de estudio, con el fin de devolver la calidad de vida a aquellos animales que han sufrido una amputación y también recuperar la capacidad para realizar sus actividades a lo largo de su vida. En el modelo desarrollado para este artículo, se trata de dar una alternativa a las prótesis rígidas que se manejan actualmente.

Palabras clave: Prótesis, diseño, análisis con elemento finito.

\section{Introduction}

In this article, we present the preliminary design of a prosthesis developed to replace the missing part of the left front extremity in a female Cervus nippon, and analyze the viability of the device based on the results obtained in the simulation of physical tests: static and temperature. In this way it will be possible to improve the stability and at the same time the quality of life of the animal, thus having a functional and adaptable design for veterinary applications in other species that present similar problems.

There are different designs in animal prostheses, however, they have similarities in terms of the dynamics they present. In the design developed for this article we propose an alternative to rigid prostheses that are currently handled, adding flexion at the time of lifting the limb, in this way the animal's walking may be more natural and probably perform the activities that it normally did. The prosthesis is totally mechanical due to the adversities of different nature that 
could be faced in the animal's daily live, uses an elastic band to contract the section of the hinge when the extremity is lifted and maintain stability when it is resting on the ground.

The prosthesis will be printed in 3D with an ABS filament. The chosen material should be able to withstand the climatic and physical conditions that the animal can face within its habitat. Due to the mechanical properties it offers, since it tends to be resilient, in addition to presenting a high hardness and resistance to heat, ABS turned out to be the most suitable material for the task.

\section{Theoretical framework}

\subsection{Subject of study and dimensions}

The study subject is a female Cervus Nippon, approximately 6 years old, and weighing $29 \mathrm{~kg}$. The amputation's place: left front femur, approximately $5 \mathrm{~cm}$ from the second joint (elbow). The amputation's place is $5 \mathrm{~cm}$ from point $\mathrm{f}$ in segment $\mathrm{f}-\mathrm{g}$, indicated in figure 1 . The measurements of the subject of study are: total length 950 to $1,800 \mathrm{~mm}$, length of the tail 75 to $130 \mathrm{~mm}$, shoulder height 640 to 1,090 mm (Medellín et al., 2000).

\subsection{Anatomy of the upper extremities.}

In figure 2 we can observe the bony disposition of a deer's limb. For the purposes of this project we will focus on joints $\mathrm{f}$ and $\mathrm{g}$, since these are the ones that still conserve and that will be simulated respectively. 


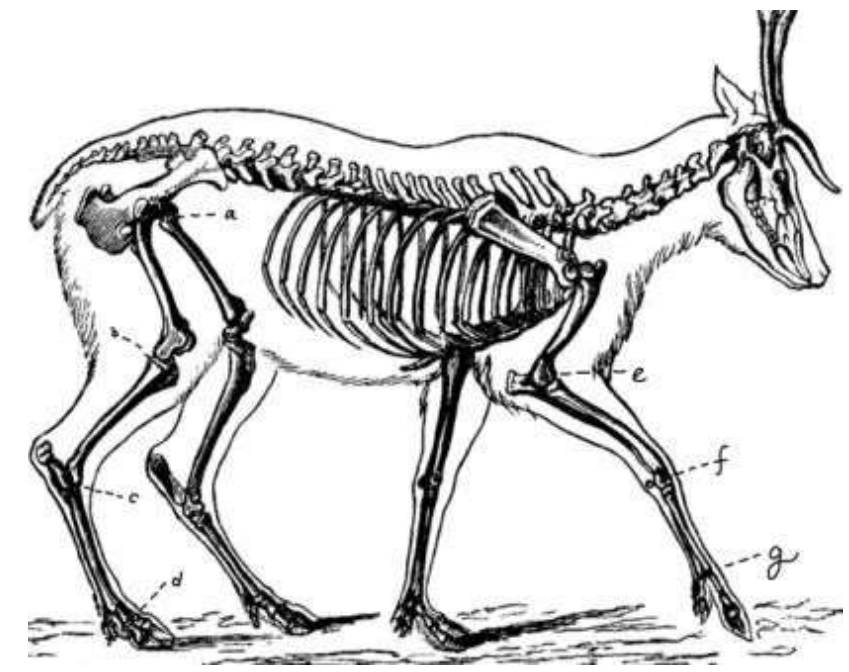

Fig. 1. Joints of the extremities of a deer (The Book Worm, 2020).

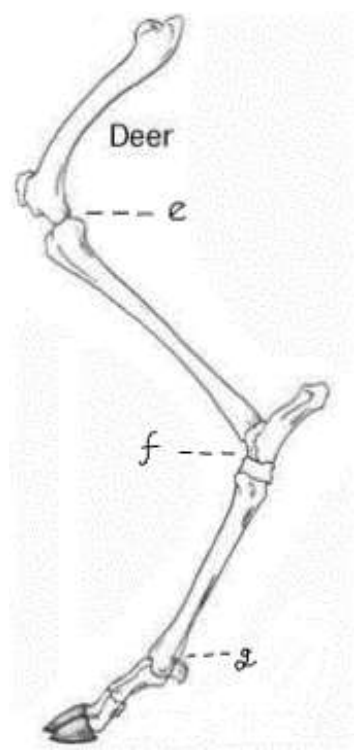

Fig. 2. Bone structure of a deer limb (Myers et al., 2021)

At walking and resting its paw on the ground, the $\mathrm{g}$ joint of the deer flexes to soften the impact, similar to our squatting walk (Murray State University, n.d.). This is important since to emulate as much as possible the normal functioning of the limb results in a more enjoyable and healthy walking both physically and psychologically for the deer. 


\subsection{ABS material.}

$\mathrm{ABS}$ is the name given to a family of thermoplastics, its acronym derives from the three monomers used to produce it: acrylonitrile, butadiene and styrene (Ohji et al., 2015). The ABS structure is a mixture of a vitreous copolymer (styrene-acrylonitrile) and an elastic compound, mainly the butadiene polymer. ABS is a more resilient plastic, than polystyrene due to nitrile groups, for example. This material is very polar, so it attracts itself allowing the opposite charges of the nitrile groups to stabilize.

\subsection{Finite element analysis with Solidworks.}

The Finite Element Analysis (FEA) is the simulation of any given physical phenomenon using the numerical technique called Finite Element Method (FEM). Engineers use it to reduce the number of physical prototypes and experiments and optimize components in their design phase to develop better products, in a faster way (Fish \& Belytschko, 2009). Solidworks uses the finite element analysis, the model can be visualized and its behavior predicted under real working conditions. Presenting as an advantage the reduction of the cost in the tests, advancing the commercialization since it reduces the number of cycles of development of the same one and in turn the improvement of the product faster.

The static analyzes are based on two conditions: 1) Static assumption; which implies that the charges are applied slowly and gradually until they reach their full magnitudes and 2) linearity: regarding the relationship between charges and the response of the material (CARMAN, 2014).

Solidworks thermal analysis, consists in the application of the finite element method to calculate the temperature distribution in a solid structure, based on the heat loads (inputs), heat loss (outputs) and resistance to thermal contact (barriers), according to Dassault Systèmes (2010). 


\section{Methodology}

Methodology consists in three parts:

Part I: For this prosthetic's device development we have designed a model which emulates the function and characteristics of the lost extremity of our study object, conformed by several pieces in order to form the final assemble described below (figure 3).
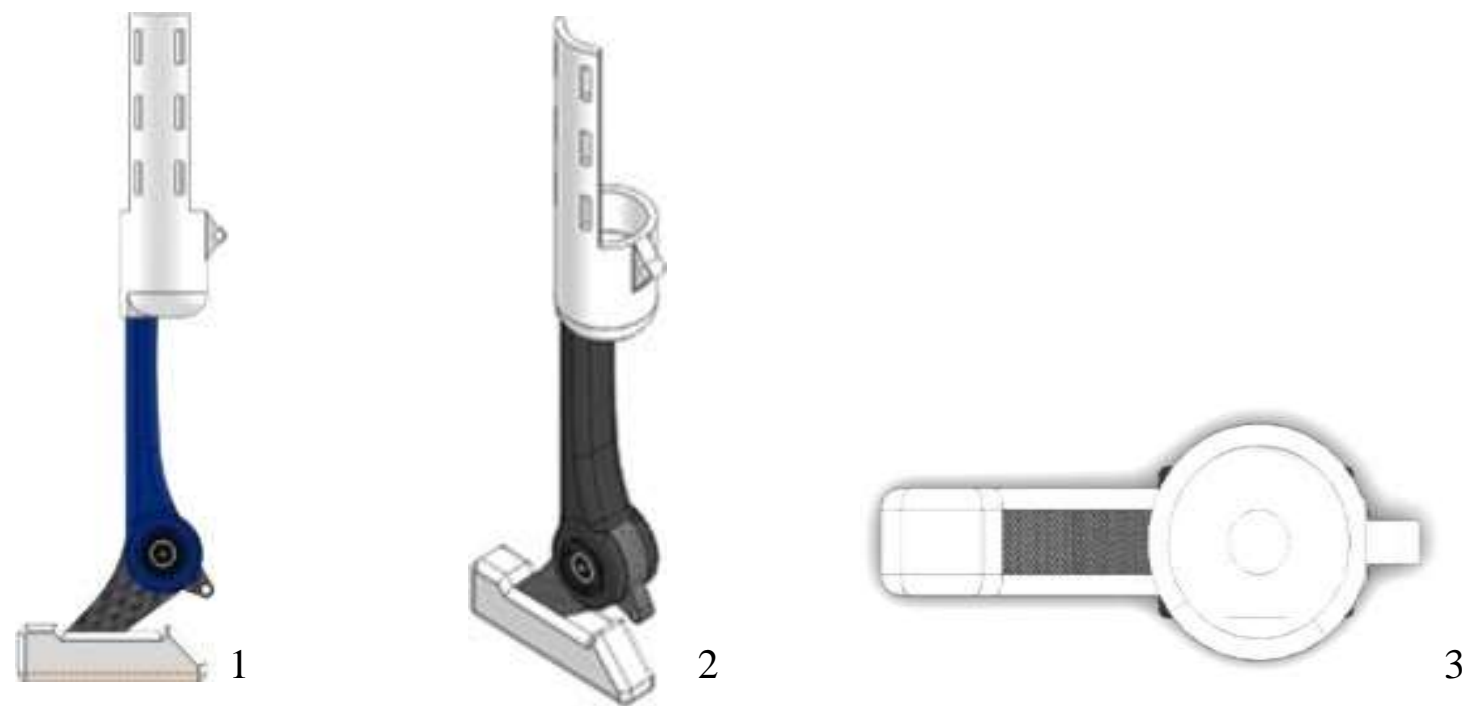

Fig. 3. Modeling of the prosthesis. 1) Frontal view. 2) Isometric view. 3) Superior view.

Part II: To make the design of the prosthetic device we examinated our study case and the problematic which represents in the amputation of our study object to reach a design which offers a solution in the optimum way to the problematic.

Part III. We proceeded to make a static analysis to the assemble of the prosthetic device with the finite element simulation with Solidworks as our design software, applying the ABS material included on the material library software; placing a subjection to the corresponding part as the base of the assemble and applying different charges in the support section of the amputation, later we created the dimension of our assembly before run the simulation. Next we 
made a thermal analysis applying temperatures that will be daily exposed to the device, creating the dimension before running the simulation as we did with the last studio.

\section{Results}

The simulation of the studies made with Solidworks gave us the results below. Figure 4 represents the suffering deformation which takes place) applying a charge of $300 \mathrm{~N}$, it has been taken 3 important points where the charge has affected the model and it has been plotted in the figure, it happens in the same way with the figure 5 now applying a charge of $75 \mathrm{~N}$.

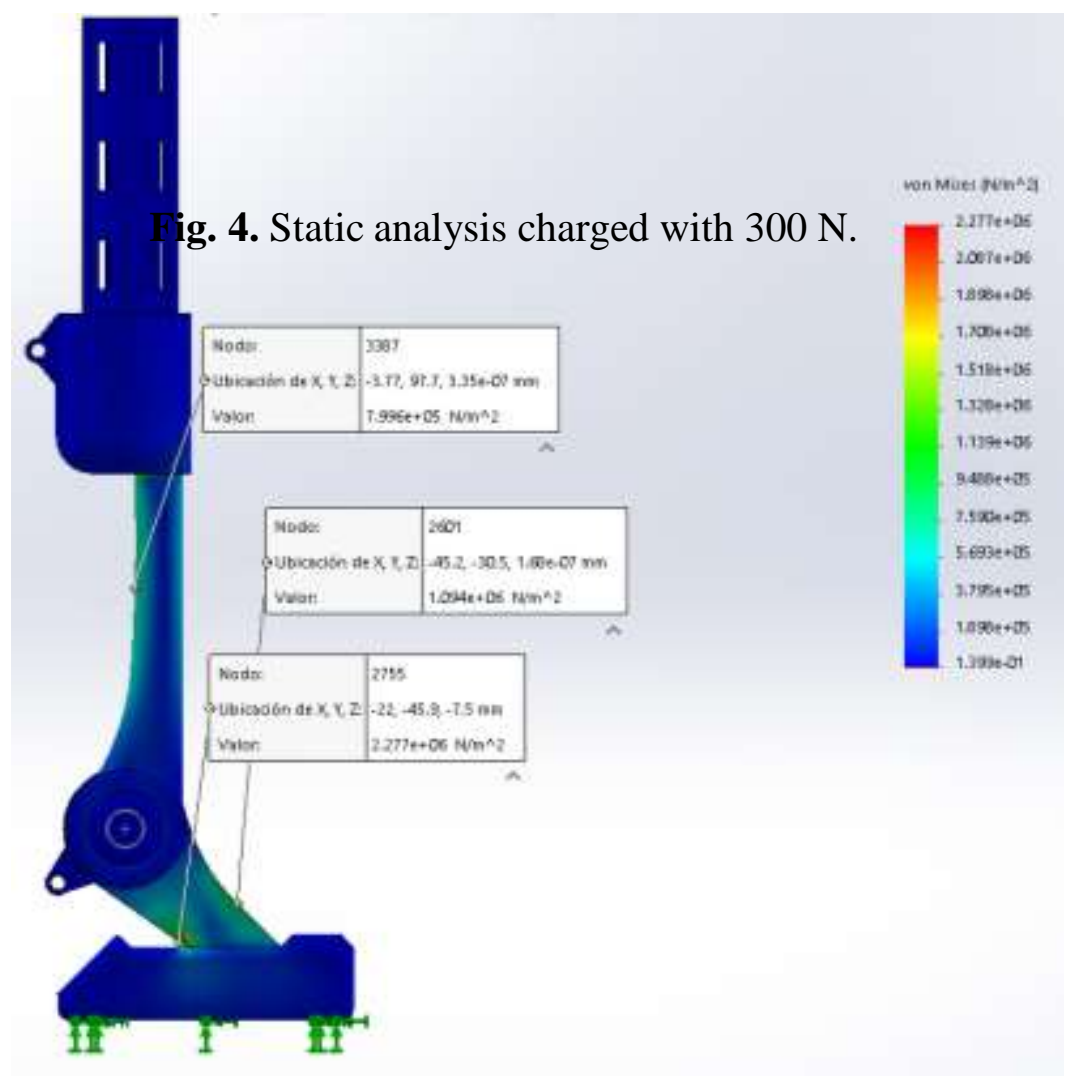




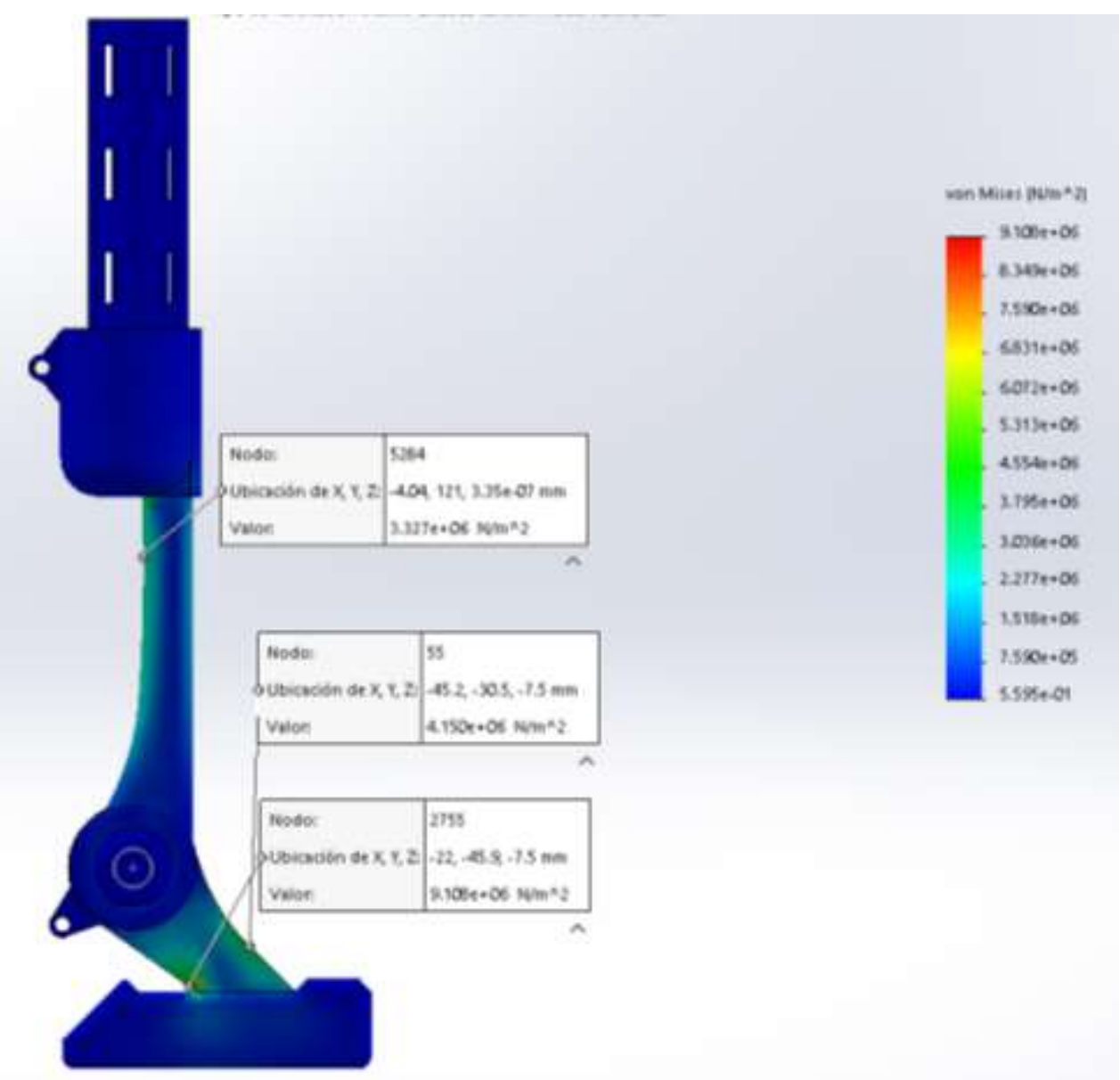

Fig. 5. Static analysis charged with $75 \mathrm{~N}$.

Figure 6 shows the results of the thermic study where we applied the temperatures which it will be exposed everyday as well in the environment and with the amputated contact of our study object. On figure 6 we show the graphic of our thermal study and its results. In the simulated cases there is not an apparent damage due to static fatigue in the prosthesis, even subjecting it into a higher effort than the one provided by the weight of the deer in one leg ( 300 $\mathrm{N})$. There is not any thermal damage into the apartments due to thermal loads higher than $40{ }^{\circ} \mathrm{C}$ (Hermosillo Sonora's temperature, where the experiment was simulated). 


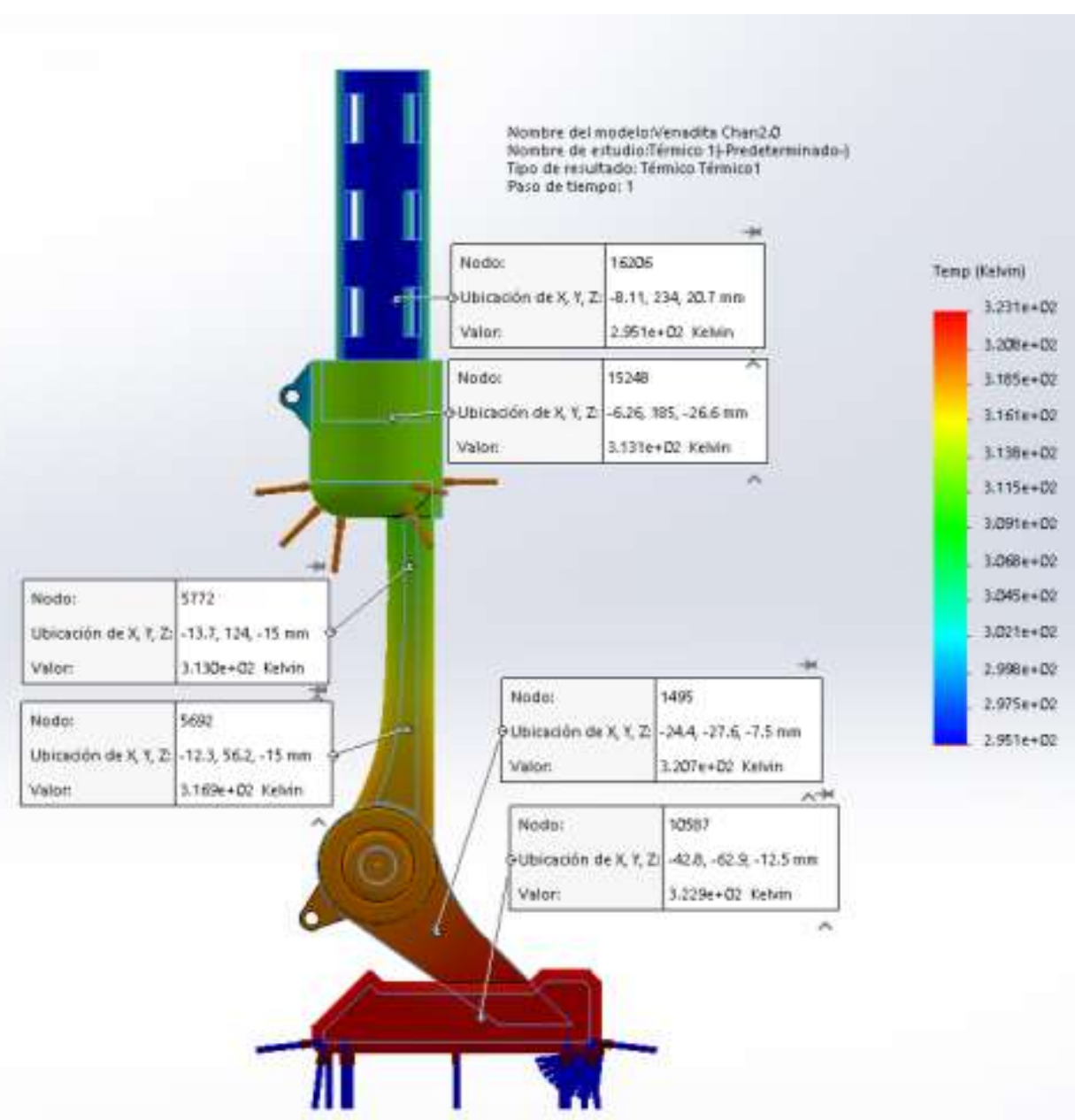

Fig. 6. Thermal analysis of the assembling.

\section{Conclusions}

Based on the collected evidence, we can see that the prosthesis made with ABS filament is completely compatible to fulfill its purpose and perform the task of adding support and improving stability to the animal, as well as providing an alternative to rigid prostheses, since the proposed design consists of a joint to add mobility, as well as making the movement more instinctive and natural. The prosthesis was subjected to different analyzes in Solidworks 
Simulation of static and thermal type yielding satisfactory results to the forces applied, even considering the animal's weight and the high temperatures found in Hermosillo Sonora. Our device offers a high resistance to those factors. In addition, its main advantage which is the replacement of parts in a simple way in case of long-term use due to the fact that its design is made up of multiple pieces. Another of the advantages offered is its low cost production, thanks to the ABS filament costs and the ease to create new parts due to $3 \mathrm{D}$ printing. It is worth mentioning that the testing period continues with the next stage which consists of the physical tests in our subject and thus determine the changes to be made in this device in the future. We believe that our study could help into the creation of veterinary prostheses with higher quality and performance, being applicable not only in deer but adaptable to other animals.

\section{References}

CARMAN. (2014). Solidworks Análisis Estático | Validaciones de diseño mecánico. CARMAN® Official Site. Retrieved 26 October 2020, from https://grupocarman.com/blog/2014/02/13/solidworks-analisis-estatico/.

Dassault Systèmes. (2010). Thermal Analysis. Concord: Solidworks. Retrieved from https://www.solidworks.com/sw/docs/thermal_2010_eng_final.pdf

Fish, J., \& Belytschko, T. (2009). A first course in finite elements (2nd ed.). John Wiley \& Sons.

Medellín, R., Gómez, H., Álvarez, J., \& Oliveras, A. (2000). Vertebrados superiores exóticos en México: diversidad, distribución y efectos potenciales. Informe final SNIB-CONABIO. México: UNAM.

Murray State University. Deer Biomechanics. Campus.murraystate.edu. Retrieved 25 October 2020, from https://bit.ly/3Cj7Snq.

Myers, P., Espinosa, R., Parr, C., Jones, T., Hammond, G., \& Dewey, T. (2021). The Animal Diversity Web. Animal Diversity Web. Retrieved 20 June 2021, from https://animaldiversity.org/accounts/Sciuridae/specimens/collections/contributors/anatomi cal_images/feet_and_legs/posture/?start=15.

Ohji, T., Halbig, M., Kirihara, S., Singh, M., \& Wang, J. (2015). Advanced Processing and Manufacturing Technologies for Nanostructured and Multifunctional Materials II (1st ed.). Wiley-American Ceramic Society. 
The Book Worm. (2020). Alamy Stock Photo [Image]. Retrieved 25 April 2020, from https://bit.ly/3vJ7OdP.

Cómo citar:

MONTIJO-VAlEnZUELA, E. E., Ruiz Navarro, A. G., Silva Contreras, A., \& Ruvalcaba Aranda, J. A. (2021). Diseño y validación con análisis de elementos finitos de una prótesis de aplicación veterinaria para Cervus nippon. Revista De Investigación Académica Sin Frontera: División De Ciencias Económicas Y Sociales, (36). https://doi.org/10.46589/rdiasf.vi36.419

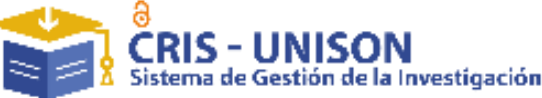

\section{lationdex} catdoget

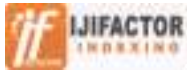

- Dialnet

LatinREV Neliti - Indonesia's Research Repository

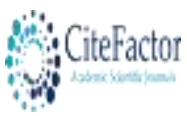
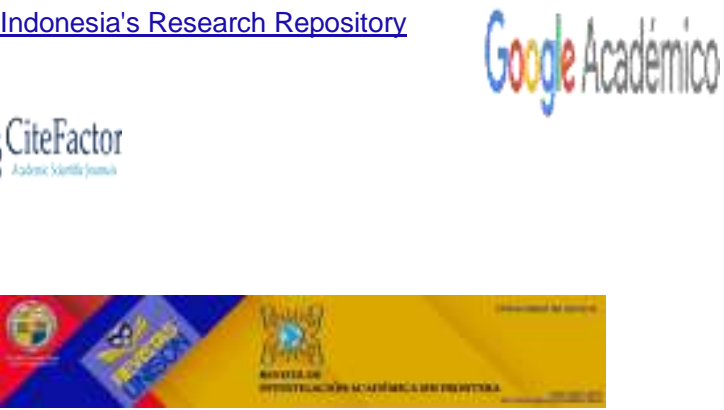